\title{
A survey identifying nutritional needs in a contemporary adult cystic fibrosis cohort
}

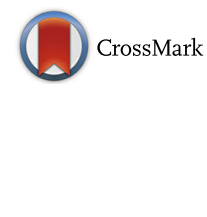

Siddhartha G. Kapnadak ${ }^{1 *}$, Kathleen J. Ramos ${ }^{1}$, Andrea M. Lopriore ${ }^{2}$, Christopher H. Goss ${ }^{1,3}$ and Moira L. Aitken ${ }^{1}$

\begin{abstract}
Background: Cystic fibrosis (CF) is a disease in which nutritional barriers are diverse and common, with malnutrition greatly influencing pulmonary trajectory and overall outcomes. Despite this, the most effective methods to optimize CF nutrition are unknown, and literature describing patients' perspectives on their specific nutritional needs is lacking, particularly in the modern era of CF care. This study aimed to identify the most important nutritional needs and desired health-improvement resources in a contemporary adult CF cohort.

Methods: A 14-question investigator-designed survey addressing nutrition concerns, preferred health-improvement resources, and dietary/exercise routines was administered to CF adults. Clinical characteristics and survey responses are presented with descriptive statistics, and responses compared by body mass index (BMI) category $\left(<18.5 \mathrm{~kg} / \mathrm{m}^{2} ; 18.5-24.99 \mathrm{~kg} / \mathrm{m}^{2} ; 25-29.99 \mathrm{~kg} / \mathrm{m}^{2} ; \geq 30 \mathrm{~kg} / \mathrm{m}^{2}\right)$, gender, and socioeconomic status using Chi square or Fisher's Exact testing.

Results: Of 66 total patients, nine (13.6\%) were underweight (BMl $<18.5 \mathrm{~kg} / \mathrm{m}^{2}$ ), while 19 (28.8\%) were overweight or obese $\left(\mathrm{BMI} \geq 25 \mathrm{~kg} / \mathrm{m}^{2}\right)$. In the overall cohort, the most common primary concern was preventing weight loss [in 20/66 patients (30.3\%)], but there were significant differences by BMI $(p<0.001)$, with the most common concern in the overweight subgroup being preventing weight gain. Fifteen (46.9\%) men (BMI mean 20.7, range $16.4-29.2 \mathrm{~kg} / \mathrm{m}^{2}$ ) listed preventing weight loss as the primary concern, compared to only $5(14.7 \%)$ women (BMI mean 18.4, range $16.2-19.9 \mathrm{~kg} / \mathrm{m}^{2}$ ), representing a trend toward a difference in primary concerns by gender $(p=0.066)$.

The most commonly desired health-improvement resource was online CF nutrition and fitness information, found in 26 patients (39.4\%) in the overall cohort, without significant differences by BMI ( $p=0.814$ ) or gender $(p=0.199)$. Financial assistance was the preferred resource in $17(26.2 \%)$, without differences by socioeconomic status $(p=0.367)$.

Conclusions: We identified a wide variety of nutritional needs in CF adults, including a high prevalence of overweight status, many patients desiring weight loss, and many seeking financial resources. Our findings support the individualization of modern-day CF nutrition programs and development of online resources, in an effort to address the heterogeneous barriers that exist in the contemporary CF population and improve outcomes in patients with the disease.
\end{abstract}

Keywords: Cystic fibrosis, Complications, Malnutrition, Body mass index, Body composition, Nutrition assessment, Nutrition therapy, Obesity

\footnotetext{
* Correspondence: skap@uw.edu

${ }^{1}$ Department of Medicine; Division of Pulmonary, Critical Care, and Sleep

Medicine, University of Washington Medical Center, 1959 NE Pacific, Campus

Box 356522, Seattle, WA 98195-6522, USA

Full list of author information is available at the end of the article
}

(c) The Author(s). 2019 Open Access This article is distributed under the terms of the Creative Commons Attribution 4.0 International License (http://creativecommons.org/licenses/by/4.0/), which permits unrestricted use, distribution, and reproduction in any medium, provided you give appropriate credit to the original author(s) and the source, provide a link to the Creative Commons license, and indicate if changes were made. The Creative Commons Public Domain Dedication waiver (http://creativecommons.org/publicdomain/zero/1.0/) applies to the data made available in this article, unless otherwise stated. 


\section{Background}

Cystic fibrosis (CF) is a multisystem disease caused by mutations in the cystic fibrosis transmembrane regulator (CFTR) gene, and represents the most common lifeshortening autosomal recessive disease in Caucasians [1]. Although $70 \%$ of mortality in CF is due to progressive lung disease, CFTR dysfunction can result in a high incidence of pancreatic exocrine insufficiency, gastrointestinal symptoms, CF-related diabetes mellitus (CFRD), and other clinically important non-pulmonary sequelae. With improved management of CF lung disease and survival, extra-pulmonary conditions have become an increasingly important cause of morbidity for patients with CF $[2,3]$.

Of the CF-associated extra-pulmonary manifestations, it can be argued that malnutrition is among the most critical. Malnutrition in CF, standardly defined as a low body mass index (BMI), has been found to be multifactorial, common, and independently associated with mortality, decreased quality of life and lung function, and poor outcomes after lung transplant [4-11].

Recognizing the significance of nutrition, the CF Foundation (CFF) has developed BMI-based nutritional goals for all patients: $\mathrm{BMI} \geq 50$ th percentile in children, $\geq 22$ $\mathrm{kg} / \mathrm{m} 2$ in adult women; and $\geq 23 \mathrm{~kg} / \mathrm{m} 2$ in adult men. Since the 1980's, significant progress has been made in optimizing nutrition in the CF population, but many individuals fall short of these goals [3, 5, 12, 13]. Moreover, although the CFF hasn't defined upper limits to BMI goals, recent data have shown that overweight status is also a concern in the contemporary CF population, particularly in patients with milder mutations [3, 14, 15]. Perhaps related to aggressive caloric supplementation, suboptimal food choices, lack of exercise, and medications, this has added an additional layer of complexity to modern CF nutritional management.

Despite the importance in CF, there are limited data on how best to optimize nutrition and fitness, particularly in the growing adult demographic which now makes up more than $50 \%$ of the CF population. Although multidisciplinary programs have been suggested $[5,16]$, it is not clear which interventions are most effective, and it has been demonstrated that dietitians vary in their clinical approaches [17-19]. Furthermore, it is clear that nutritional barriers vary significantly based on the individual, with patients facing a wide array of problems from medical issues to specific knowledge gaps and socioeconomic barriers [20, 21]. In this sense, identifying concerns on an individualized basis, and implementing patient-centered nutrition programs may be the most effective way to optimize adherence, perceptions of body image, and overall nutrition [17, 22]. However, to this point there is minimal literature describing CF patients' perspectives regarding their nutritional and fitness needs, nor is there information outlining nutrition programs designed based on patient preferences [20, 23, 24].

The objective of this study was to identify the most important nutritional concerns and desired health-improvement resources in a contemporary cohort of CF adults. Secondarily, we aimed to determine whether these identified needs differed based on specific patient characteristics including body mass index, gender, and socioeconomic status.

\section{Methods \\ Setting}

This study began as a prospective quality improvement project in our adult CF clinic, which serves patients $\geq 18$ years of age in the Northwestern United States. All outpatients seen from March 2016-August 2016 were eligible and were given the choice to participate. For patients choosing to participate, because it began as a quality improvement project, the University's Institutional Review Board did not require formal consent for prospective data collection; retrospective data review for the study was later approved without patient consent.

Clinical care in our center was per CFF guidelines, with patients evaluated every 3 months by a CF physician and at least annually by a CF-trained registered dietitian (RD). All visits included a weight measurement (BMI calculated in $\mathrm{kg} / \mathrm{m}^{2}$ ), history and examination, and medication review. Diabetes screening and assessment of vitamin levels was performed at least annually.

The following data were prospectively collected at the time of survey response: age, gender, BMI, forced expiratory volume in $1 \mathrm{~s}\left(\mathrm{FEV}_{1}\right)$, and diabetes status. CFTR genotypes were obtained from the local CFF patient registry portal. As in many other studies, receipt of United States Medicaid insurance (which provides funding for those with limited income) was used as a proxy for low socioeconomic status [25].

\section{Survey}

A 14-question survey was created to identify the most important nutritional concerns and desired health-improvement resources in our cohort (Additional file 1). The survey was designed by three CF physicians and our center's CF dietitian. All four providers personally completed the survey and edited it for completeness, clarity, and simplicity prior to implementation.

The survey was offered to all patients seen by the RD, with the same RD consistently available for questions encountered during completion. Primary nutrition concerns were assessed by rankings of the following options: 1) Preventing weight loss (or promoting weight gain); 2) Nutrition and food choice education; 3) Blood sugar management; 4) Preventing weight gain (or promoting weight loss); 5) Digestive health/pancreatic enzymes. 
Patients were also offered choices of health-improvement resources including: 1) Online access to $C F$ nutrition and fitness information; 2) A CF cookbook based on unprocessed foods; 3) Financial assistance for food and supplements; 4) Access to local food resources (e.g., food banks, meal programs).

Time spent on food preparation, exercise frequency/ duration, and questions surrounding medication use were evaluated with multiple choice questions. Patients were also asked to rate the utility of dietitian visits in the context of the patient-centered nutrition program, using a Likert scale from 1 (very helpful) to 5 (not helpful).

\section{Statistics}

Patient characteristics and survey responses were represented with descriptive statistics. Differences were assessed with student's t-test for continuous variables, allowing for unequal variances, and with Chi square or Fisher's Exact testing for categorical variables for patients with different CFTR mutation classes (Class I-III versus Class IV-V mutations). For survey responses to the main questions of interest (primary nutrition concern and preferred health-improvement resource), differences in outcome were assessed by BMI category $\left(<18.5 \mathrm{~kg} / \mathrm{m}^{2}\right.$; $\left.18.5-24.99 \mathrm{~kg} / \mathrm{m}^{2} ; \quad 25-29.99 \mathrm{~kg} / \mathrm{m}^{2} ; \geq 30 \mathrm{~kg} / \mathrm{m}^{2}\right)$, gender, and Medicaid insurance status using Chi square or Fisher's Exact testing.

\section{Results}

\section{Demographics}

A total of 66 patients (34 women, 32 men) were offered the survey during the quality improvement project and all completed it (100\% survey response rate). Fifty-four (81.8\%) were classified as having severe CF genotypes (CFTR Class I-III) (Table 1). The most common mutation was F508del, with 27 patients (40.9\%) homozygous, and $36(54.5 \%)$ heterozygous. Mean age was 32.3 years, and mean $\mathrm{FEV}_{1}$ was $59 \%$ predicted.

Pancreatic insufficiency was more common in those with severe genotypes, with $98.1 \%$ of patients with class I-III mutations taking pancreatic enzyme replacement therapy, compared to $50.0 \%$ of patients with class IV-V mutations $(p<0.001)$. Mean BMI in the overall cohort was $23.4 \mathrm{~kg} / \mathrm{m}^{2}$, without statistical difference by CFTR genotype $(p=0.099)$.

Table 1 Patient Characteristics by Cystic Fibrosis Transmembrane Regulator Mutation Status

\begin{tabular}{|c|c|c|c|c|c|c|c|}
\hline \multirow[b]{2}{*}{ Variable } & \multicolumn{2}{|c|}{ All Eligible Patients $N=66$} & \multicolumn{2}{|c|}{ CFTR Mutation Class I-III N=54 } & \multicolumn{2}{|c|}{ CFTR Mutation Class IV-V N $=12$} & \multirow[b]{2}{*}{$p$ Value } \\
\hline & Observed & $\mathrm{N}$ & Observed & $\mathrm{N}$ & Observed & $N$ & \\
\hline Age - mean (SD), years & $32.3(11.4)$ & 66 & $30.4(8.8)$ & 54 & $40.8(17.2)$ & 12 & 0.0637 \\
\hline Male gender & $32(48.5)$ & 66 & $27(50.0)$ & 54 & $5(41.7)$ & 12 & 0.601 \\
\hline Medicaid Insurance & $23(35.4)$ & 65 & $17(32.1)$ & 53 & $6(50.0)$ & 12 & 0.241 \\
\hline CFTR mutation status & & 66 & & & & & \\
\hline Homozygous Class I-III & $54(81.8)$ & & & & & & \\
\hline Heterozygous Class I-III & $12(18.2)$ & & & & & & \\
\hline Homozygous Class IV-V & $0(0)$ & & & & & & \\
\hline $\mathrm{FEV}_{1}$ - \% predicted (SD) & $59.3(23.3)$ & 66 & $57.3(22.7)$ & 54 & $68.3(24.9)$ & 12 & 0.178 \\
\hline Weight - mean (SD), kg & $66.1(14.6)$ & 66 & $63.9(11.9)$ & 54 & $76.0(21.2)$ & 12 & 0.079 \\
\hline $\mathrm{BMI}$ - mean (SD), kg/m² & $23.4(4.3)$ & 66 & $22.8(3.5)$ & 54 & $26.2(6.4)$ & 12 & 0.099 \\
\hline $\mathrm{BMI}<18.5$ & $9(13.6)$ & 66 & $7(13.0)$ & 54 & $2(16.7)$ & 12 & $0.663^{b}$ \\
\hline BMI 18.5-24.99 & $38(57.6)$ & 66 & $34(63.0)$ & 54 & $4(33.3)$ & 12 & $0.104^{b}$ \\
\hline BMI 25-29.99 & $13(19.7)$ & 66 & $11(20.4)$ & 54 & $2(16.7)$ & 12 & $1.000^{\mathrm{b}}$ \\
\hline $\mathrm{BMI} \geq 30$ & $6(9.1)$ & 66 & $2(3.7)$ & 54 & $4(33.3)$ & 12 & $0.008^{\mathrm{b}}$ \\
\hline BMI meeting CFF goal ${ }^{a}$ & $38(57.6)$ & 66 & $29(53.7)$ & 54 & $9(75.0)$ & 12 & $0.177^{\mathrm{b}}$ \\
\hline CF-related diabetes on insulin & $15(23.1)$ & 65 & $14(26.4)$ & 53 & $1(8.3)$ & 12 & $0.267^{b}$ \\
\hline CF-related PI on enzymes & $58(89.2)$ & 65 & $52(98.1)$ & 53 & $6(50.0)$ & 12 & $<0.001^{b}$ \\
\hline Prednisone use (at time of survey) & $5(7.7)$ & 65 & $5(9.4)$ & 53 & $0(0)$ & 12 & $0.575^{b}$ \\
\hline PEG tube in place & $2(3.1)$ & 65 & $1(1.9)$ & 53 & $1(8.3)$ & 12 & $0.338^{b}$ \\
\hline Nutritional supplement use & $32(49.2)$ & 65 & $26(49.1)$ & 53 & $6(50.0)$ & 12 & 0.953 \\
\hline
\end{tabular}

Data are presented as No. (\%) unless indicated otherwise. Certain background clinical data were not recorded and were thus unavailable for one individual ${ }^{a}$ CFF goal for weight is BMI $\geq 22 \mathrm{~kg} / \mathrm{m}^{2}$ for females, and $\geq 23 \mathrm{~kg} / \mathrm{m}^{2}$ for males

${ }^{\mathrm{b}}=$ Fisher's exact test

CF cystic fibrosis, SD standard deviation, CFTR cystic fibrosis transmembrane conductance regulator gene, FEV1 forced expiratory volume in one second, BMI body mass index, CFF Cystic Fibrosis Foundation, PI pancreatic insufficiency, PEG percutaneous endoscopic gastrostomy 
Thirty-eight patients (57.6\%) had BMIs meeting CFF goals ( $\geq 22 \mathrm{~kg} / \mathrm{m}^{2}$ for women, $\geq 23 \mathrm{~kg} / \mathrm{m}^{2}$ for men). Only nine patients $(13.6 \%)$ were underweight $(\mathrm{BMI}<18.5 \mathrm{~kg} /$ $\mathrm{m}^{2}$ ). Conversely, overweight status was relatively common, with 19 patients $(28.8 \%)$ having $B M I \geq 25 \mathrm{~kg} / \mathrm{m}^{2}$. Obesity (BMI $\geq 30 \mathrm{~kg} / \mathrm{m}^{2}$ ) was more common in those with mild mutations [4 of 5 patients (33\%) with mild mutations versus 2 of 54 (3.7\%) patients with severe mutations, $p=0.008]$.

\section{Overall survey data}

Survey completion time was $<10 \mathrm{~min}$ for all 66 patients. Participants rated the patient-centered RD program highly, with mean score 2.1 out of 5 , where 1 indicated "very helpful".

Time spent on food preparation varied widely, with 19 patients $(29.2 \%)$ spending greater than $45 \mathrm{~min}$ daily, 19 (29.2\%) 31-45 min daily, 24 (36.9\%) 11-30 min daily, and 3 (4.6\%) $0-10$ min daily.

Patients reported exercising a mean of 3.6 days/week, with a majority reporting duration of $>30$ min per session. Specific exercise patterns varied, with 11 (19.6\%) patients reporting mean exercise durations $>60 \mathrm{~min}$ daily, and 6 (10.7\%) reporting durations $0-15$ min daily.
Walking, running, and strength training were the most popular forms of exercise.

\section{Primary nutrition concerns and choice of health- improvement resources}

In the entire cohort, the most common primary nutrition concern was preventing weight loss, found in 20 (30.3\%) of respondents (Fig. 1a). Nutrition education was also a common response, answered in 15 (22.7\%) patients in the cohort.

The most commonly sought out health-improvement resource in the overall cohort was online access to $\mathrm{CF}$ nutrition and fitness information, with 26 patients (39.4\%) listing this as their preferred choice of the offered programs (Fig. 2a). Seventeen patients (26.2\%) listed financial assistance for food and supplements as their preferred choice.

\section{Differences by body mass index}

Differences in primary nutrition concern by BMI category are displayed in Fig. 1b. All patients with $\mathrm{BMI}<18.5 \mathrm{~kg} /$ $\mathrm{m} 2(n=9)$ reported preventing weight loss as their primary concern. In contrast, in patients with BMI 25-29.99 $(n=13)$ and $\geq 30 \mathrm{~kg} / \mathrm{m} 2 \quad(n=6)$, preventing weight gain

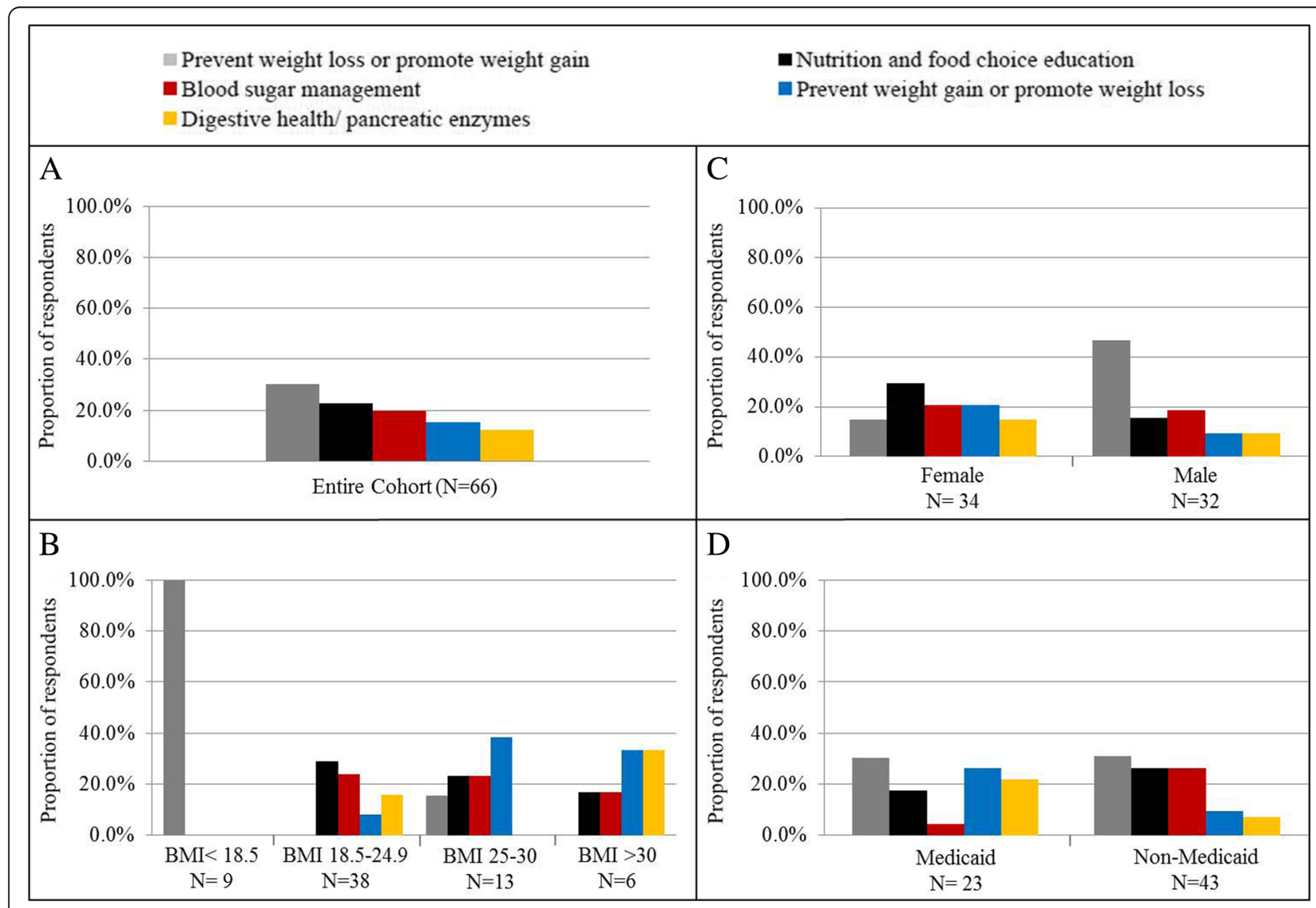

Fig. 1 Primary nutrition concerns. a In the entire cohort; b) By BMI (in $\left.\mathrm{kg} / \mathrm{m}^{2}\right)$; c) By gender; d) By insurance status, (BMI = Body mass index) 
Online access to CF nutrition and fitness information

- Financial assistance for food and supplements
- CF Cookbook

access to local food resources (e.g. food banks, meal programs)
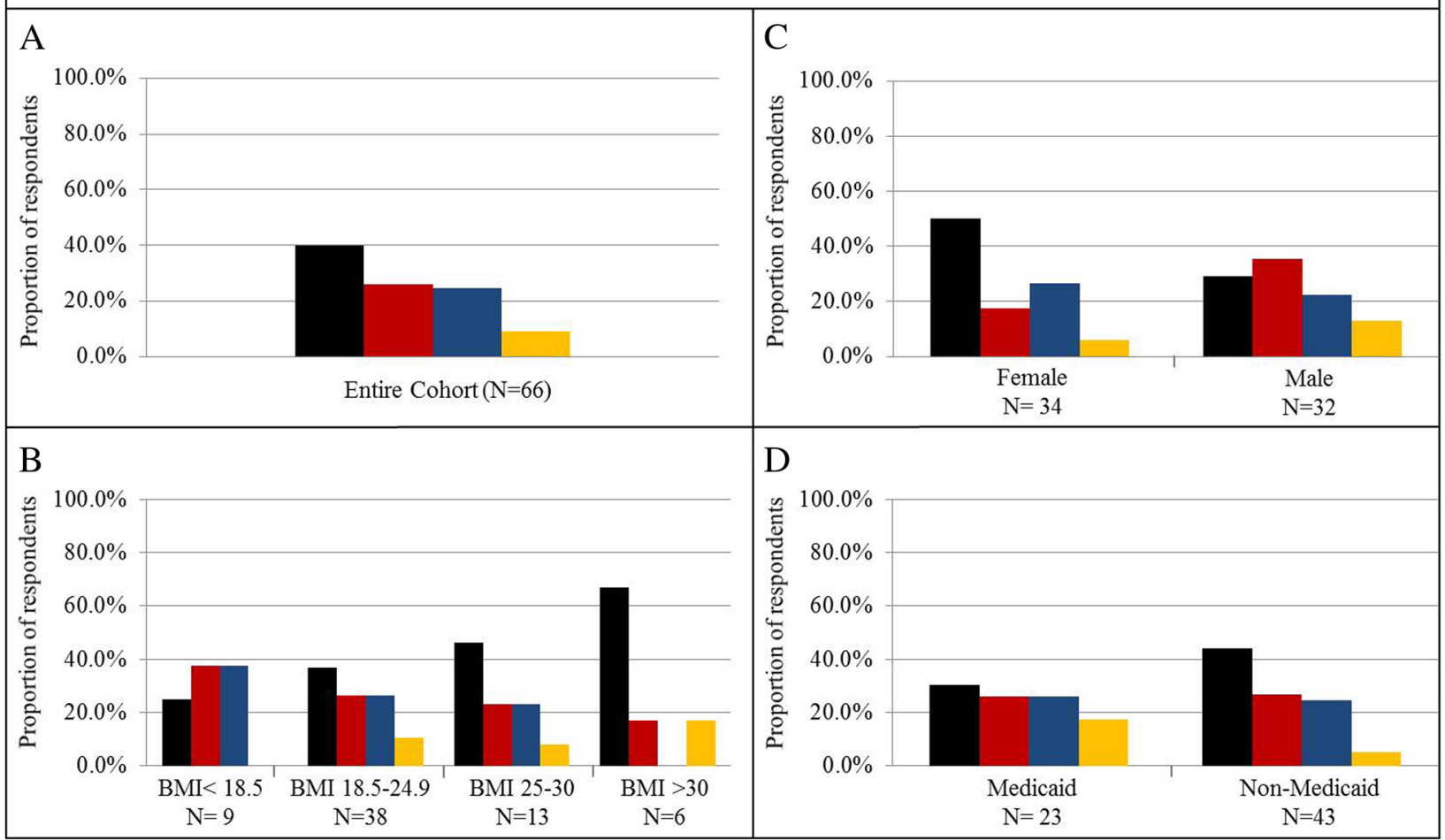

B

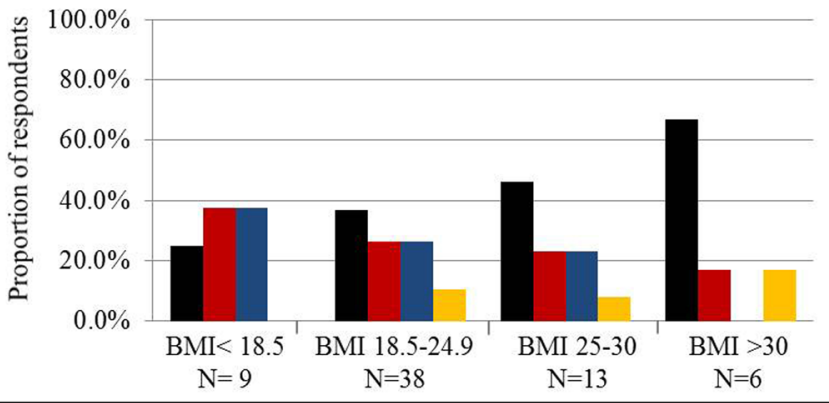

$\mathrm{D}$

Fig. 2 Preferred health-improvement resources. a In entire cohort; b) By BMI (in $\left.\mathrm{kg} / \mathrm{m}^{2}\right)$; c) By gender; $\left.\mathbf{d}\right)$ By insurance status, (BMI= Body mass index, CF = Cystic fibrosis)

was the most common concern, found in 38.5 and $33.3 \%$ of patients, respectively $(p<0.001$ for comparisons by BMI category, Fisher's Exact testing).

Differences in preferred health-improvement resources are displayed in Fig. 2b. Financial assistance was a more common response in underweight patients than the overall cohort, found in $37.5 \%$ of respondents with a $\mathrm{BMI}<18.5 \mathrm{~kg} / \mathrm{m}^{2}$. In patients with $\mathrm{BMI} \geq 30 \mathrm{~kg} / \mathrm{m}^{2}$, $66.7 \%$ listed online access to CF nutrition and fitness information as their top program choice. Despite these qualitative differences compared to the overall cohort, there were no significant differences in choice of health improvement resources by BMI status $(p=0.814)$.

\section{Differences by gender}

Mean BMI was $23.1 \mathrm{~kg} / \mathrm{m}^{2}$ in women and $23.7 \mathrm{~kg} / \mathrm{m}^{2}$ in men. The most common primary nutrition concern among women was nutrition education, found in $29.4 \%$ of female respondents (Fig. 1c). Among men, preventing weight loss was the most common primary nutrition concern, and was a much more common response in men (46.9\% of respondents) compared to women $(14.7 \%$ of respondents). Conversely, preventing weight gain was a more common response among women, listed as the primary nutrition concern in $20.6 \%$ of women compared to $9.4 \%$ of men. This represented a trend toward, but not a statistical difference in primary nutrition concerns by gender $(p=0.066)$.

The preferred health-improvement resources also varied qualitatively by gender, with $50.0 \%$ of women listing online access to CF nutrition and fitness information as their preferred program, compared to $29.0 \%$ of men (Fig. 2c). The most commonly sought out resource in men was financial assistance for food and supplements, found in $35.5 \%$ of male respondents. Despite the qualitative differences, there was no statistical difference in preferred health-improvement resources by gender $(p=0.199)$.

\section{Differences by socioeconomic status}

Of 66 patients in the entire cohort, 23 (34.8\%) were on Medicaid. Mean BMI was $23.8 \mathrm{~kg} / \mathrm{m}^{2}$ in the Medicaid subgroup and $23.1 \mathrm{~kg} / \mathrm{m}^{2}$ in the Non-Medicaid subgroup $(p=0.582)$. Underweight status was more common in the Medicaid subgroup, with $21.7 \%$ of Medicaid patients having $\mathrm{BMI}<18.5 \mathrm{~kg} / \mathrm{m}^{2}$, compared to only $9.5 \%$ of 
patients in the non-Medicaid subgroup. Additionally, obesity was more common in the Medicaid subgroup, with $17.4 \%$ of Medicaid patients having a BMI $>30 \mathrm{~kg} / \mathrm{m}^{2}$, compared to only $4.8 \%$ of patients in the non-Medicaid subgroup. Despite these trends, comparisons did not meet statistical significance $(p=0.260$ and $p=0.174$, respectively).

Preventing weight loss was the most common nutrition concern in both the Medicaid and non-Medicaid subgroups, but the percentage of patients who were most concerned about preventing weight gain was significantly higher in the Medicaid subgroup, found in $26.1 \%$ of Medicaid compared to $9.5 \%$ of non-Medicaid respondents ( $p=0.048)$ (Fig. 1d).

In both the Medicaid and non-Medicaid subgroups, the most commonly chosen health-improvement resource was online access to CF nutrition and fitness information. Surprisingly, financial assistance for food and supplements was the preferred resource for a similar percentage of non-Medicaid (26.8\%) and Medicaid (26.1\%) patients, indicating no difference in health-improvement resource preferences by insurance status $(p=0.367)$.

\section{Discussion}

Improving nutrition is a critical component of CF care, with malnutrition having clear associations with poor outcomes in patients with the disease $[4,5,10,11]$. Classically, this has been targeted through a combination of increasing caloric intake and supplements, optimizing pancreatic enzyme replacement, and pulmonary/medical management, with general aim of maintaining BMI above CFF goals [5, 14]. Although multidisciplinary nutrition programs are suggested [5], to this point there is limited knowledge regarding the optimal methods or programs specifically desired by patients. In this study, we describe a patient-centered model that identified specific nutritional concerns and desired programs in a contemporary population of CF adults. The program was popular among participants and identified heterogeneous concerns, nutritional barriers, and desired interventions based on patient-specific factors in our cohort.

There are many barriers to achieving optimal nutrition in patients with CF $[5,9]$. In addition to pancreatic exocrine insufficiency, present in at least 85\% [3], CF patients have been shown to have markedly increased basal energy expenditure, a problem related to chronic pulmonary infection which can worsen in more advanced stages of lung disease. Additional medical barriers include dyspnea and mechanical effects of lung hyperinflation, gastrointestinal symptoms, and CFRD. Together with weight loss, lean body mass can also be disproportionately impacted by suboptimal dietary choices and lack of exercise, the latter of which may worsen in those with advanced lung disease [26-29].
Furthermore, psychosocial obstacles may be more prevalent in $\mathrm{CF}$, including depression, low socioeconomic status, medical knowledge gaps, and issues with adherence to medical/nutritional programs [3, 21, 30-34].

Given the complexity of these barriers, it is natural that poor nutritional status in CF would be a multifaceted problem. Our findings are consistent with this notion. Importantly, in our cohort of CF adults, we found a high prevalence of overweight status. Although more than half met traditional CFF BMI goals, 28.8\% were overweight, and $9.1 \%$ obese. This finding is consistent with previously demonstrated longitudinal trends in CF [14], with our percentages even exceeding prior estimates of the prevalence of overweight status [3, 15]. Furthermore, in our study, a significant portion of patients actually desired weight loss, with about $15 \%$ of the cohort listing this as their primary nutritional concern, a percentage that approached $40 \%$ in patients with a BMI $>25 \mathrm{~kg} / \mathrm{m}^{2}$. The problem of CF-associated obesity, on one hand, may reflect improvements in pulmonary management and a general ageing of the CF population, both of which can be considered strong accomplishments in the disease's history. On the other hand, although general CF nutritional trends have improved with average BMI in adults now above goal, the prevalence of obesity in our study supports the concept that the modern era of CF nutrition has evolved considerably. Recognition of the heterogeneity of nutritional barriers may become even more important as the $\mathrm{CF}$ population continues to age and cardiovascular risks increase $[35,36]$, where personalizing nutrition programs may become integral to improving CF outcomes.

The potential benefits of a patient-centered nutrition program approach are broad. Firstly, it has been demonstrated that CF patients respond well to assuming more control of their treatment plans, including recent data showing effectiveness of online and smartphone-based health-management programs [37, 38]. Secondly, there are studies showing that body image is an important component of well-being for CF children, adolescents, and adults and that improving body satisfaction may increase both adherence and quality of life [22, 39-42]. Body satisfaction is naturally influenced by subjective medical and psychosocial factors, with optimal satisfaction likely best attained by first identifying the specific barriers at hand $[22,43]$. In our cohort we did find an array of nutritional and exercise habits, goals, and desired resources. As with previous reports, we identified gender differences in weight goals, with CF men more often concerned about preventing weight loss, and women more often concerned about preventing weight gain $[41,43]$. Online access to CF nutrition and fitness resources was consistently the most sought-after health improvement resource, but many patients preferred 
other programs including direct education from CF dietitians, recipes via a CF cookbook, or financial assistance. The variety of needs presented in this study support the assertion that individualizing $\mathrm{CF}$ nutrition programs may be a valuable means of improving overall nutrition outcomes.

An important consideration in the patient-centered model presented here are financial and psychosocial barriers. Access to insurance coverage and financial limitations pose a challenge to many CF patients, with CFF registry data demonstrating that nearly half of individuals receive some portion of coverage through federal or state-funded programs, and low socioeconomic status having been associated with a variety of adverse outcomes [3, 21, 31, 44]. In our Medicaid cohort, although mean BMI was $23.8 \mathrm{~kg} / \mathrm{m}^{2}$, it is noteworthy that nearly $60 \%$ fell outside of the "optimal" BMI range of 18.5-25 $\mathrm{kg} / \mathrm{m}^{2}$, including roughly $35 \%$ overweight or obese, and $22 \%$ underweight. More than $1 / 3$ of our cohort was on Medicaid, further suggesting that this may be a CF subset of particular importance when trying to optimize overall nutritional outcomes. In our study, financial assistance and local food resources were commonly desired health-improvement resources even among non-Medicaid patients, lending additional credence to the importance of addressing financial barriers in every patient. Especially considering the expenses and time constraints related to $\mathrm{CF}$ care, patient-centered nutrition programs would likely benefit from early assessment of financial concerns, along with education and other psychosocial barriers as they pertain to nutrition and fitness.

There were several limitations of this study, the first of which was a small sample size. The lack of statistically significant differences between subgroups (gender, BMI, socioeconomic status) may have been due to the study being underpowered. Larger studies on the topic are needed, but this exploratory analysis is the first to identify specific, individual nutrition concerns in a modern-day CF adult cohort, and thus represents a foundation on which further patient-centered nutrition programs may be developed. Second, this study used a convenience sample of adults attending our CF clinic with, on average, moderate lung disease. Although identifying nutritional needs may be a valuable tool in all CF cohorts, our specific findings are thus less generalizable to CF children, as well as in adults with very severe lung disease or post-transplant, where specific findings may differ. Likewise, in regards to socioeconomic comparisons, our study necessarily examined CF patients within the United States healthcare system, and while socioeconomic obstacles exist globally, the specific findings may vary in other systems. Finally, this study used an investigator-designed survey tool that has not been validated. Given that (to our knowledge) no similar validated tools exist, we consider it a first step in determining CF patient-specific nutritional needs, but since it was not an interventional study, our data cannot be used to determine the effectiveness of the suggested interventions. Future studies are needed to apply patient-specific interventions in CF using similar tools, while also examining nutritional and overall outcomes.

\section{Conclusions}

In summary, in this study we describe nutritional demographics and concerns in a contemporary cohort of CF adults, finding a relatively high prevalence of overweight status, and recognizing a wide variety of barriers to optimizing nutrition. We describe a patient-centered model that allowed identification of specific concerns, goals, and desired health-improvement resources. The problem of overweight status in CF adults should be appreciated, and future studies are needed to implement, refine, and assess the efficacy of patient-centered programs, with a goal of improving nutritional and overall outcomes in patients with $\mathrm{CF}$.

\section{Additional file}

Additional file 1: Survey of nutritional needs. (DOCX $24 \mathrm{~kb}$ )

\section{Abbreviations}

BM: Body mass index; CF: Cystic fibrosis; CFF: Cystic fibrosis foundation; CFRD: Cystic fibrosis related diabetes; CFTR: Cystic fibrosis transmembrane regulator; $\mathrm{FEV}_{1}$ : Forced expiratory volume in one second; PEG: Percutaneous gastrostomy; PI: Pancreatic insufficiency; RD: Registered dietitian;

SD: Standard deviation

\section{Acknowledgements}

Not applicable.

\section{Funding}

This research did not receive any specific grant from funding agencies in the public, commercial, or not-for-profit sectors.

\section{Availability of data and materials}

The datasets used and analyzed for the current study are available from the corresponding author on reasonable request.

\section{Authors' contributions}

SK was involved with study design and drafted the manuscript. KR was involved with study design, analyzed and interpreted the data, and edited the manuscript. AL was involved with study design and edited the manuscript. CG was involved with study design, analyzed and interpreted the data, and edited the manuscript. MA was involved with study design and edited the manuscript. All authors read and approved the final manuscript.

\section{Ethics approval and consent to participate}

Data was collected prospectively as a quality improvement project within our center's cystic fibrosis clinic. The University of Washington's Human Subjects Division approved retrospective data review for the study without patient consent.

\section{Consent for publication}

The University of Washington's Human Subjects Division approved publication without patient consent.

Competing interests

The authors declare that they have no competing interests. 


\section{Publisher's Note}

Springer Nature remains neutral with regard to jurisdictional claims in published maps and institutional affiliations.

\section{Author details \\ 'Department of Medicine; Division of Pulmonary, Critical Care, and Sleep Medicine, University of Washington Medical Center, 1959 NE Pacific, Campus Box 356522, Seattle, WA 98195-6522, USA. ${ }^{2}$ Department of Nutrition, University of Washington Medical Center, 1959 NE Pacific, Campus Box 356522, Seattle, WA 98195-6522, USA. ${ }^{3}$ Department of Pediatrics; Division of Pulmonary and Sleep Medicine, University of Washington Medical Center, 1959 NE Pacific, Campus Box 356522, Seattle, WA 98195-6522, USA.}

\section{Received: 14 March 2018 Accepted: 13 December 2018}

Published online: 07 January 2019

\section{References}

1. Ratjen F, Doring G. Cystic fibrosis. Lancet. 2003;361:681-9.

2. Elborn JS. Cystic fibrosis. Lancet. 2016;388:2519-31.

3. Cystic Fibrosis Foundation Patient Registry 2015. Annual Data Report. Bethesda: Cystic Fibrosis Foundation; 2015.

4. Corey M, McLaughlin FJ, Williams M, Levison H. A comparison of survival, growth, and pulmonary function in patients with cystic fibrosis in Boston and Toronto. J Clin Epidemiol. 1988;41:583-91.

5. Turck D, Braegger CP, Colombo C, Declercq D, Morton A, Pancheva R, et al. ESPEN-ESPGHAN-ECFS guidelines on nutrition care for infants, children, and adults with cystic fibrosis. Clin Nutr. 2016;35:557-77.

6. Shoff SM, Tluczek A, Laxova A, Farrell PM, Lai HJ. Nutritional status is associated with health-related quality of life in children with cystic fibrosis aged 9-19 years. J Cyst Fibros. 2013;12:746-53.

7. Lederer DJ, Wilt JS, D'Ovidio F, Bacchetta MD, Shah L, Ravichandran S, et al. Obesity and underweight are associated with an increased risk of death after lung transplantation. Am J Respir Crit Care Med. 2009:180:887-95.

8. Peterson ML, Jacobs DR Jr, Milla CE. Longitudinal changes in growth parameters are correlated with changes in pulmonary function in children with cystic fibrosis. Pediatrics. 2003;112:588-92.

9. Elborn JS, Bell SC. Nutrition and survival in cystic fibrosis. Thorax. 1996;51:971-2.

10. Sharma R, Florea VG, Bolger AP, Doehner W, Florea ND, Coats AJ, et al. Wasting as an independent predictor of mortality in patients with cystic fibrosis. Thorax. 2001;56:746-50

11. Beker LT, Russek-Cohen E, Fink RJ. Stature as a prognostic factor in cystic fibrosis survival. J Am Diet Assoc. 2001:101:438-42.

12. White $H$, Morton AM, Peckham DG, Conway SP. Dietary intakes in adult patients with cystic fibrosis--do they achieve guidelines? J Cyst Fibros. 2004:3:1-7.

13. Connett GJ, Pike KC. Nutritional outcomes in cystic fibrosis - are we doing enough? Paediatr Respir Rev. 2015;16(Suppl 1):31-4.

14. Stephenson AL, Mannik LA, Walsh S, Brotherwood M, Robert R, Darling PB, et al. Longitudinal trends in nutritional status and the relation between lung function and BMI in cystic fibrosis: a population-based cohort study. Am J Clin Nutr. 2013:97:872-7.

15. Kastner-Cole D, Palmer CN, Ogston SA, Mehta A, Mukhopadhyay S. Overweight and obesity in deltaF508 homozygous cystic fibrosis. J Pediatr. 2005;147:402-4.

16. Stallings VA, Stark $L$, Robinson KA, Feranchak AP, Quinton H. Evidencebased practice recommendations for nutrition-related management of children and adults with cystic fibrosis and pancreatic insufficiency: results of a systematic review. J Am Diet Assoc. 2008;108:832-9.

17. O'Brien $\mathrm{CE}$, Harden $\mathrm{H}$, Com $\mathrm{G}$. A survey of nutrition practices for patients with cystic fibrosis. Nutr Clin Pract. 2013;28:237-41.

18. Stark LJ, Opipari-Arrigan L, Quittner AL, Bean J, Powers SW. The effects of an intensive behavior and nutrition intervention compared to standard of care on weight outcomes in CF. Pediatr Pulmonol. 2011:46:31-5.

19. Milla CE. Nutrition and lung disease in cystic fibrosis. Clin Chest Med. 2007; 28:319-30.

20. McDonald CM, Haberman D, Brown N. Self-efficacy: empowering parents of children with cystic fibrosis. J Cyst Fibros. 2013;12:538-43.

21. Schechter MS, Shelton BJ, Margolis PA, Fitzsimmons SC. The association of socioeconomic status with outcomes in cystic fibrosis patients in the United States. Am J Respir Crit Care Med. 2001:163:1331-7.

22. Simon SL, Duncan CL, Horky SC, Nick TG, Castro MM, Riekert KA. Body satisfaction, nutritional adherence, and quality of life in youth with cystic fibrosis. Pediatr Pulmonol. 2011;46:1085-92.
23. Hegarty M, Macdonald J, Watter P, Wilson C. Quality of life in young people with cystic fibrosis: effects of hospitalization, age and gender, and differences in parent/child perceptions. Child Care Health Dev. 2009;35:462-8.

24. Borawska-Kowalczyk U, Sands D. Determinants of health-related quality of life in polish patients with CF - adolescents' and parents' perspectives. Dev Period Med. 2015;19:127-36.

25. Quon BS, Psoter K, Mayer-Hamblett N, Aitken ML, Li Cl, Goss CH. Disparities in access to lung transplantation for patients with cystic fibrosis by socioeconomic status. Am J Respir Crit Care Med. 2012:186:1008-13.

26. King SJ, Nyulasi IB, Strauss BJ, Kotsimbos T, Bailey M, Wilson JW. Fat-free mass depletion in cystic fibrosis: associated with lung disease severity but poorly detected by body mass index. Nutrition. 2010;26:753-9.

27. Lucidi V, Bizzarri C, Alghisi F, Bella S, Russo B, Ubertini G, et al. Bone and body composition analyzed by dual-energy X-ray absorptiometry (DXA) in clinical and nutritional evaluation of young patients with cystic fibrosis: a cross-sectional study. BMC Pediatr. 2009;9:61

28. Thobani A, Alvarez JA, Blair S, Jackson K, Gottlieb ER, Walker S, et al. Higher mobility scores in patients with cystic fibrosis are associated with better lung function. Pulm Med. 2015;2015:423219.

29. Collaco JM, Blackman SM, Raraigh KS, Morrow CB, Cutting GR, Paranjape SM Self-reported exercise and longitudinal outcomes in cystic fibrosis: a retrospective cohort study. BMC Pulm Med. 2014:14:159.

30. Dill EJ, Dawson R, Sellers DE, Robinson WM, Sawicki GS. Longitudinal trends in health-related quality of life in adults with cystic fibrosis. Chest. 2013;144: 981-9.

31. Stephenson A, Hux J, Tullis E, Austin PC, Corey M, Ray J. Socioeconomic status and risk of hospitalization among individuals with cystic fibrosis in Ontario, Canada. Pediatr Pulmonol. 2011:46:376-84.

32. Schechter MS, McColley SA, Silva S, Haselkorn T, Konstan MW, Wagener JS. Association of socioeconomic status with the use of chronic therapies and healthcare utilization in children with cystic fibrosis. J Pediatr. 2009:155:634639.e1-4.

33. Stapleton DR, Gurrin LC, Zubrick SR, Silburn SR, Sherriff JL, Sly PD. What do children with cystic fibrosis and their parents know about nutrition and pancreatic enzymes? J Am Diet Assoc. 2000;100:1494-500.

34. Henley LD, Hill ID. Errors, gaps, and misconceptions in the disease-related knowledge of cystic fibrosis patients and their families. Pediatrics. 1990:85: 1008-14.

35. Slesinski MJ, Gloninger MF, Costantino JP, Orenstein DM. Lipid levels in adults with cystic fibrosis. J Am Diet Assoc. 1994;94:402-8.

36. Rhodes B, Nash EF, Tullis E, Pencharz PB, Brotherwood M, Dupuis A, et al. Prevalence of dyslipidemia in adults with cystic fibrosis. J Cyst Fibros. 2010;9: 24-8

37. Cox NS, Alison JA, Button BM, Wilson JW, Holland AE. Feasibility and acceptability of an internet-based program to promote physical activity in adults with cystic fibrosis. Respir Care. 2015:60:422-9.

38. Hilliard ME, Hahn A, Ridge AK, Eakin MN, Riekert KA. User preferences and design recommendations for an mHealth app to promote cystic fibrosis self-management. JMIR Mhealth Uhealth. 2014;2:e44

39. Abbott J, Conway S, Etherington C, Fitzjohn J, Gee L, Morton A, et al. Perceived body image and eating behavior in young adults with cystic fibrosis and their healthy peers. J Behav Med. 2000;23:501-17.

40. Wenninger $K$, Weiss $C$, Wahn U, Staab D. Body image in cystic fibrosis development of a brief diagnostic scale. J Behav Med. 2003;26:81-94.

41. Walters S. Sex differences in weight perception and nutritional behaviour in adults with cystic fibrosis. J Hum Nutr Diet. 2001;14:83-91.

42. Truby H, Paxton AS. Body image and dieting behavior in cystic fibrosis. Pediatrics. 2001;107:E92.

43. Tierney S. Body image and cystic fibrosis: a critical review. Body image. 2012;9:12-9

44. O'Connor GT, Quinton HB, Kahn R, Robichaud P, Maddock J, Lever T, et al. Case-mix adjustment for evaluation of mortality in cystic fibrosis. Pediatr Pulmonol. 2002:33:99-105. 